\title{
知識の抽象化と階層化による複数台自律エージェントの 階層的転移学習とその効果
}

\author{
Hierarchical Transfer Learning Framework by Utilizing Ontology \\ and Multi-Agent Transfer Learning
}

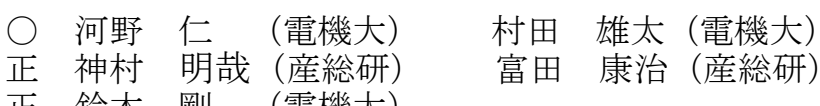

正 鈴木 剛 (電機大)

Hitoshi KONO, Tokyo Denki University, hitoshi@nrl.c.dendai.ac.jp Yuta MURATA, Tokyo Denki University

Akiya KAMIMURA, National Institute of Advanced Industrial Science and Technology Kohji TOMITA, National Institute of Advanced Industrial Science and Technology Tsuyoshi SUZUKI, Tokyo Denki University

\begin{abstract}
In recent years, a multi-agent robot system (MARS) utilizing reinforcement learning and transfer learning has been deployed in real-world situations. Autonomous agents of MARS obtain behavior autonomously by multi-agent reinforcement learning method, and a transfer learning method enables to reuse the knowledge of other robot's behavior such as cooperative behavior. Those methodologies, however, have not been fully discussed systematically. Hence, we propose the knowledge co-creation framework leveraging the transfer learning and a cloud computing. Until now, we developed a Hierarchical Transfer Learning (HTL) as core technology of a knowledge co-creation and indicated effectiveness of the HTL in a dynamic multi agent environment. However, an effectiveness of our proposed HTL depends on transfer rate and approximation accuracy of knowledge generated by artificial neural network. In this paper, we evaluate the effectiveness of the HTL in new artificial neural network settings.
\end{abstract}

Key Words: Knowledge co-creation, Transfer learning, Multi-agent reinforcement learning, Autonomous robot

\section{1. 緒言}

近年，マルチロボットシステム（Multi-Agent Robot System: MARS) の実世界応用が検討され, 多くの研究が行われている. 協調的な行動が可能な MARS は，様々なタスクを人の代わり に遂行する事が期待され，過重労働による健康障害防止等に 貢献すると考えられる。しかし，予め動作がプログラムされ た MARS は我々の生活するような動的環境において，適応的 に行動できるとは言い難い。また，様々な環境に適応するプ ログラムを開発する場合は，考慮する環境の状態が多く，設 計・開発コストが増大寸る。そこで，強化学習を応用し，複 数台のロボットが環境に対する行動や協調行動を学習するマ ルチエージェント強化学習 (Multi-agent reinforcement learning : MARL）が提案されている[1]. MARL はロボットのような実 エージェントに限定した手法ではないが，本研究では MARS への応用を考える. MARL は過去の研究により，動的環境に おける有用性が示されてきた[2,3]. しかし，MARL にも実世 界応用には以下のような課題がある.

・学習に多くの試行回数と時間が必要.

・獲得する知識は学習機会に依存.

・獲得した知識の保存量の限界。

これらの問題に対し，クラウドロボティクスのように高速ネ ットワーク網と外部大規模計算機リソース（以下クラウド） を活用して，ロボット間で獲得知識の共有を行う研究が行わ れている[4].これは，ロボット同士が学習した知識を共有す ることで，学習の分散化や知識の再利用が可能である。しか し,クラウドを活用した MARL は, 方法論が確立していない. 著者らは，へテロジーニアスな MARS がクラウドを用いて， 学習した知識を共有・再利用・再学習する自律ロボットによ る知識共創システムを提案している[5,6]. これまで, 知識共創 システムの中核となる技術として，階層的転移学習を提案し
有用性を示した[6]. 階層的転移学習は, 転移学習とオントロ ジを統合し, 知識の抽象化に伴う階層化を行う $[7,8]$. さらに, ヘテロジーニアスなロボットが，階層化された知識を適宜選 択し再学習・再共有する事により，様々なロボット間におけ る知識の再利用を可能にする (図 1). 著者らは, 階層的転移学 習を活用し様々なロボットが知識を共創するシステムの実現 を目指している。獲得した知識のデータ軽量化と汎用化のた めに，人工ニューラルネットワーク (Artificial neural network : ANN)による知識の関数近似を行う[6]. しかし，これまでの結 果では，ANNの近似精度が，知識を再利用するロボットのパ フォーマンスに影響する問題点があった。そこで，本稿では ANN による獲得知識の近似精度を高めた計算機実験を行い, 階層的転移学習の効果を検証したので報告する.

本研究の提案手法は，実ロボットへの実装を目的としてい るが，本稿では計算機実験を行い，仮想エージェントを用い る。以下，本稿では，実ロボットや仮想エージェントも含め エージェントと呼ぶ.

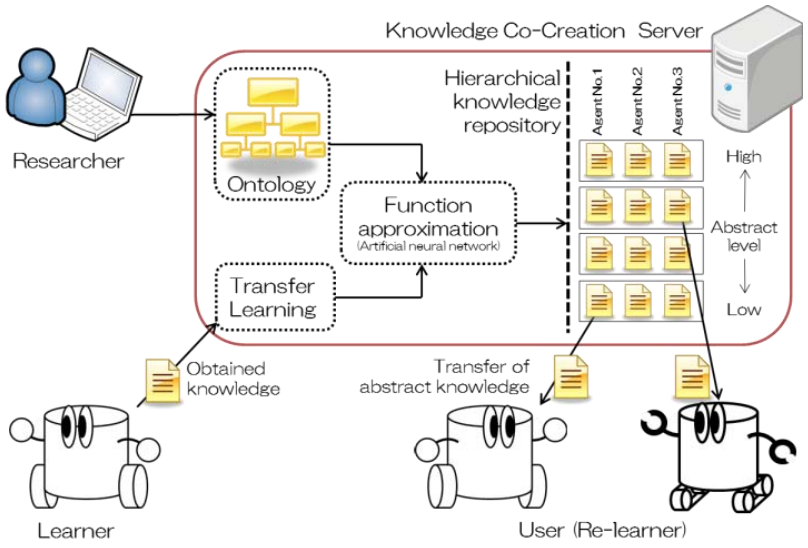

Fig. 1 Simplified representation of proposed system 


\section{2. 強化学習と転移学習}

\section{1 強化学習}

強化学習は，タスク達成時の報酬をもとに，試行錯誤しな がら最適行動を後発的に学習する。エージェントに行動を組 み込む必要がなく, ハンドコーディングより良い性能の行動 を獲得する場合がある。本研究では Q 学習を採用する [9]．ま た，行動選択手法にはボルツマン選択を用いる。

本研究において,「知識」はエージェントが学習した環境に 対する行動の対，すなわち $Q(s, a)$ と記述する方策を示す.

\section{2 転移学習}

強化学習をはじめ，学習システムでは知識の再利用を行う 手法が提案されている。 その中でも，自律エージェントでの 利用を前提とした転移学習が Taylor らにより提案されている [7]. 転移学習は，エージェントが Source task と呼ばれる環 境において予備的な学習を行う。次に, Target task と呼ばれ る新たな環境において, エージェントが Source task で獲得し た知識を活用し，新たな環境においても適応的に振る舞うこ とを可能にするフレームワークである.

Taylor らにより提案された転移学習は, Inter-task mappingにより知識の再利用を行う. Inter-task mappingは, Target task におけるエージェントの環境状態集合 $\boldsymbol{S}_{\text {target }}$ と行 動の集合 $\boldsymbol{A}_{\text {target }}$, Source task におけるエージェントのそれ ぞれの集合 $\boldsymbol{S}_{\text {source }}$ と $\boldsymbol{A}_{\text {source }}$ にマッピングするメカニズムであ る.言い換えると, Source task で獲得した知識を Target task のエージェントでどのように利用するかの変換規則を定義す る. Inter-task mappingは, 原理的にへテロジーニアスなエ ージェントで利用可能であるが, 多くの研究がエージェント 1 台対 1 台のマッピングとなっており，へテロジーニアスな多 台数エージェント間における Inter-task mapping が確立され ていない. 既存の手法において, エージェント数が増加する と Inter-task mapping の作業量も増大寸る. この問題に対し て，著者らの提案手法を次章に述べる.

\section{1 知識の抽象化と階層化}

\section{3. 階層的転移学習}

階層的転移学習は，2.2 節にて述べた Inter-task mapping におけるエージェント間の行動や環境状態のマッピングをオ ントロジにより統合する事で実現する[6].

オントロジとはもともと哲学用語であるが，工学的応用の 観点からは“概念化の明示的な規約” と定義される [8]. 本研 究においても, オントロジの工学的応用の側面を利用する. すなわち，物事の概念を分類，関係性を定義し，他者と共有・ 合意する手法として利用する．近年のオントロジは，様々な 関係性の定義や表現方法が確立しつつあるが，本研究での応 用法は単純に “is-a” 関係を利用する. Inter-task mapping の行動や環境状態をインスタンスと解釈し，それらがどの上 位概念(抽象化された行動)に属しているかを分類する手法と して活用寸る(図 2). また，本提案手法における「抽象化」と は, 図 2 においてェージェントの具体的な行動を, オントロ ジ上の上位概念（上位クラス）に分類する事を意味する．同 様に，エージェントが観測可能な環境状態もオントロジで分 類する.また，段階的に抽象化された階層上でオリジナルの 知識を抽象化し, 段階的に抽象化する事を「階層化」と呼ぶ.

\section{2 知識の再利用方法}

エージェントが Source taskにて Q 学習より獲得した知識 $Q^{s}(s, a)$ を用いて, エージェントが Target task で行動を選択

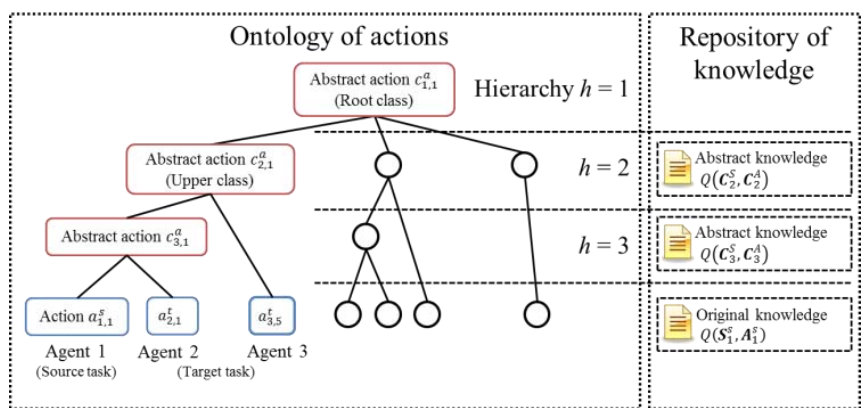

Fig. 2 Ontology and abstract knowledge

する場合, $Q^{s}(s, a)$ と Target task における獲得知識 $Q^{t}(s, a)$ を統合した $Q(s, a)$ を用いる(式(1))。なお， Target taskにおけ る知識 $Q^{t}(s, a)$ の更新は, 式(1)を用いず, 一般的な 1 ステップ $\mathrm{Q}$ 学習により更新を行う。ここで, 本稿において $Q^{s}(s, a)$ は階 層的転移学習から得られた抽象化知識であることに注意が必 要である. 転移率 $\tau\left(\in \mathbb{R}^{+}\right)$は, Source task にて獲得した行 動価值に対する Target task の行動価值の大きさを調整する パラメータとして定義する。したがって，転移先のエージェ ントにおける行動選択は，ボルツマン選択を基に，式(1)を用 いて式(2)として定義する。ここで， $\chi_{S}\left(s^{t}\right)$ と $\chi_{A}\left(a^{t}\right)$ は, Target task の環境状態 $s^{t}$ と行動 $s^{t}$ を, Source task の $s$ とaにマッピン グする Inter-task mapping である.

$$
\begin{gathered}
Q\left(s^{t}, a^{t}\right)=Q^{t}\left(s^{t}, a^{t}\right)+\tau \cdot Q^{s}\left(\chi_{S}\left(s^{t}\right), \chi_{A}\left(s^{t}\right)\right) \\
p\left(a^{t} \mid s^{t}\right)=\frac{e^{\left\{Q\left(s^{t}, a^{t}\right) / T\right\}}}{\sum_{b \in A} e^{\left\{\left(s^{t}, a^{t}\right) / T\right\}}}
\end{gathered}
$$

\section{4. 計算機実験}

提案手法の有用性を評価するために，計算機実験による検 証を行う。本実験の目的は，ヘテロジーニアスな MARL シス テムにおいて, 階層的転移学習により, 知識の再利用が行え ることを確認する。また， Target taskにおいて，転移無しの エージェントより, 階層的転移学習を用いたエージェントの 方が良いパフォーマンスを示すことを確認する. 本実験では, 評価関数として次節に記す追跡問題を採用する.

\section{1 環境とェージェントの設定}

追跡問題は，グリッドワールド内をハンターが移動し，獲 物を捕まえるゲームであり，ハンターが獲物を捕まえるまで のステップ数により評価する. 本稿では, Gasser や Arai ら の研究を参考に環境設定を行った $[10,11]$. 環境設定として, グリッドワールドの大きさは $7 \times 7$ に設定した(図 $3(\mathrm{a})$ ). ハン ターを 2 台, 獲物を 1 台グリッドワールドに配置する. 各エ ージェンとの初期座標は図 3(a)のように固定とする。 ハンタ 一は Q 学習により環境状態に対する行動を学習する事が可能 であり，獲物は学習を行わず，基本的にはランダムな行動を 取る。獲物の捕獲状態は，図 3(b)のように，2 台のハンターが 同時に獲物と隣り合う座標に位置した時とする．捕獲状態に 到達するとハンターは報酬を得ることができ，初期座標から 捕獲状態までを 1 episode と呼ぶ.また, エージェントの行動 順序は ハンター $1 \rightarrow$ ハンター $2 \rightarrow$ 獲物 の順とする. 各エ ージェントが 1 回行動を行った状態を 1 step と呼ぶ.

本実験では，へテロジーニアスなエージェントを再現する ために図 $3(\mathrm{~d}) \sim(\mathrm{f})$ の様な異なる移動特性を持つ 3 つのハンター 
を用いて追跡問題を行う. 各ハンターは，図中に示寸矢印の 方向に 1 マスまたは 2 マスの移動が可能である. 獲物も同様 に, 図 3(c)の様に行動が可能である. 各エージェンとは, 視界 範囲が定められており, 図 3(c) (f)に示すグレーにマスクされ た範囲で他エージェントの認識が可能である。獲物は，すで に述べたようにランダムな行動を行うが視界内にハンターが 存在する場合はハンターと逆方向に移動する逃避行動を取る。

Source task のハンターは, Q 学習とボルツマン選択を用い て学習と行動を行う. Target task においては, Q 学習と式 (1),(2)の階層的転移学習用に変更したボルツマン選択を用い て学習と行動を行う.

\section{2 実験条件}

本実験では，3 種のハンターを用いて，そのうち 2 台を MARS として構成し, 表 1 に示寸計 6 種類の条件により計算 機実験を行う. 表 1 中の実験条件のアルファベットの枝番は, 獲得した知識を転移する方向を逆に設定している実験条件で ある。これは，ハンターの組合せによる転移の容易さを検証 する為である。また，実験条件 A に関してはホモジーニアス （以下：ホモ）同士における転移学習を行うが, Source task と Target task を含めた環境としては, ヘテロジーニアス（以 下 : ヘテロ）な環境である。

知識を転移する際, Source task で獲得された知識を直接転 移を行わず，一度 ANNにより関数近似を行い, データ量を軽 減してから転移を行う。著者らのこれまでの研究では, ANN の近似精度が課題であった[6]. そこで, 本稿の実験では, ANN の入力層と出力層の值の範囲を, 強化学習の行動価值の取り うる範囲に調整した. また, ANN の十分な学習回数を設定し, 事前に関数近似精度を検証した状態で実験を行う。

いずれの実験条件においても，Q 学習におけるパラメータ は, 学習率 $\alpha=0.7$, 割引率 $\gamma=0.9$, 報酬 $r=1$, 温度定数 $T=$ 0.01 とする。転移学習における転移率 $\tau$ は各実験で $0.01,0.1$ 1.0 の 3 種類を設定した. Source taskにおいて 10000 エピソー ドの学習を行い，ハンター 1 が獲得した知識は Target task の ハンター 1 へ転移される.ハンター 2 に関しても同様である. Target taskにおいても 10000 エピソードの実験を行う. Target task では実験結果に確率的な挙動が含まれるため, 各実験条件 において 10 回試行し，その平均を結果とする.

本実験の評価指標として，転移の結果であるジャンプスタ 一トと収束值を用いる $[7,10]$. ジャンプスタートは, 初期エピ ソードにおいて転移無のエージェントと比べて, 転移有のエ ージェントの目標達成（獲物の捕獲）がどれだけ早いかとい う指標である。また，収束值は転移有と転移無においてエー ジェントが同様のパフォーマンスを獲得できるかという指標 である. 本実験では, 9901 エピソードから 10000 エピソード までの平均ステップ数を収束值とした.

\section{3 実験用オントロジ}

本実験において，オントロジは予めハンター内部にプログ ラムしておく. Target task のハンターは, 自身にプログラム されたオントロジを参照し, 抽象化された知識を利用する. 本実験で利用するオントロジを図 4 に示す. 本オントロジの 設計指針としては，エージェント間で同じ方向の行動(インス タンス)に関しては，同じクラスヘマッピングする．異なる行 動に関しては，移動方向が近い行動同士をクラスにマッピン グする. 図 3(d) (f) と図 4 の行動名との対応は, 図 3(d) ( f $)$ の 上部方向への矢印は前進(Move to front)を基準に, 図中の一は

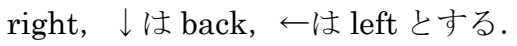

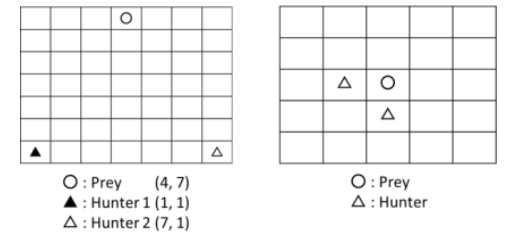

(a) Grid world

(d) Hunter 1

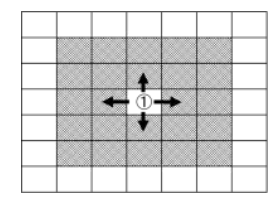

(b)Capturing state

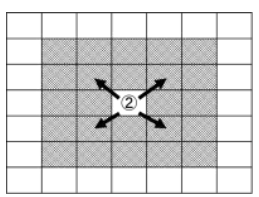

(e) Hunter 2

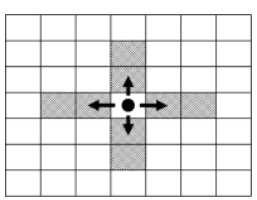

(c) Prey

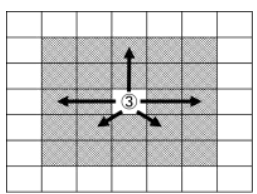

(f) Hunter 3
Fig. 3 Settings of pursuit game

Table 1 Experimental conditions

\begin{tabular}{cccc}
\hline $\begin{array}{c}\text { Class of } \\
\text { heterogenety }\end{array}$ & $\begin{array}{c}\text { Experimental } \\
\text { condition }\end{array}$ & $\begin{array}{c}\text { Source task } \\
\text { Hunter1 Hunter2 }\end{array}$ & $\begin{array}{c}\text { Target task } \\
\text { Hunter1 Hunter2 }\end{array}$ \\
\hline \hline Homo-Homo & A-1 & Agent 1, Agent.1 & Agent 2, Agent 2 \\
\cline { 2 - 4 } & A-2 & Agent 2, Agent 2 & Agent 1, Agent 1 \\
\hline \multirow{2}{*}{ Homo-Hetero } & B-1 & Agent 1, Agent 1 & Agent 1, Agent 2 \\
\cline { 2 - 4 } & B-2 & Agent 1, Agent 2 & Agent 1, Agent 1 \\
\hline Hetero-Hetero & C-1 & Agent 1, Agent 2 & Agent 2, Agent 3 \\
\cline { 2 - 4 } & C-2 & Agent 2, Agent 3 & Agent 1, Agent 2 \\
\hline
\end{tabular}

\section{5. 実験結果と考察}

各実験条件から得られた, 学習曲線の比較を図 $5(\mathrm{a}) \sim(\mathrm{f})$ に示 す. 図 5 の学習曲線は縦軸に, 獲物の捕獲までに要した step 数，横軸に学習の繰り返し回数を示す.また波形の確率的な 分散が多く，比較しにくくなるため Stineman 関数により近 似した波形を学習曲線として示す。これらの学習曲線から, 全ての実験条件において, 転移率を 0.01 から上昇させるとジ ヤンプスタートが顕著に現れることが見て取れる．特に，転 移率 1.0 においてはどの実験条件においても, Source task の 収束值と同等, もしくはそれ以下の捕獲 step 数が初期 episode から現れている。これは，異なるエージェントの知識を再利 用することで, Target task のエージェントが初期 episode か ら高いパフォーマンスを発揮できる事を意味する.

次に, 最も転移の効果が現れた, 転移率 1.0 におけるジャン プスタートと収束值の数值比較を表 2 と表 3 に示す. 全ての 実験条件において，少なくとも $70 \%$ 以上のジャンプスタート が現れ，知識転移の効果が明らかである。ささらに，表 3 にお ける転移率 1.0 における収束值の比較では, Target task の全 ての収束值が Source task の収束值を下回る結果が得られた. 単に転移学習を行う事で, 強化学習より良い知識を獲得した と言える。これは，転移の際に ANNによる関数近似を行った 影響だと考えられる. ANN の関数近似により, Source task の知識がよりブラッシュアップされた可能性が考えられる.

\section{6. 結言}

本研究では, ヘテロジーニアスな MARS における知識の共 有や再利用を目的に, 階層的転移学習を提案し, ANN の近似 精度を高めた状態で計算機実験を行った。実験結果から，ど の実験条件においても, 転移率 1.0 では明らかなジャンプスタ 


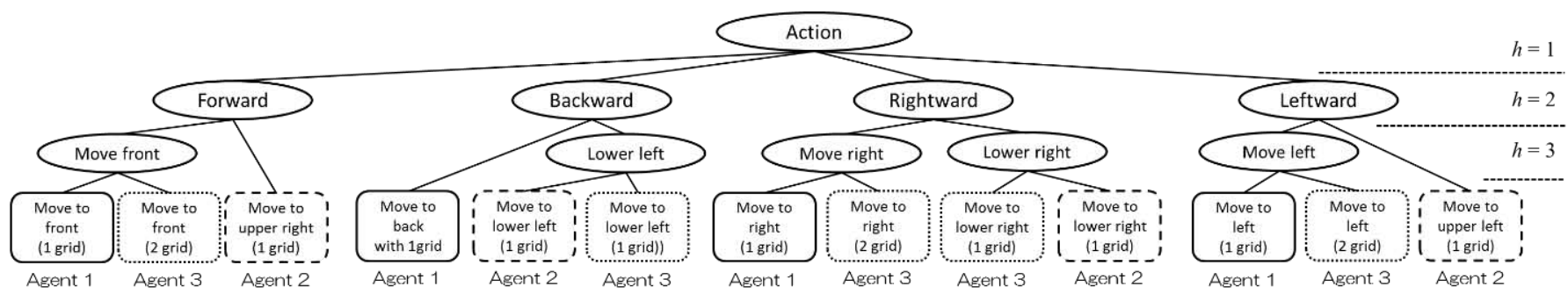

Fig. 4 Ontology of actions with three hierarchy

一トが現れ, かつ, 転移無の学習曲線とも近い収束值が得ら れた。これにより，オントロジを用いた転移学習手法である 階層的転移学習の有用性が示された. 今後, 実エージェント （ロボット）を用いた検証が必要である。

本稿にて，手法の有用性が示されたため，今後は知識の共 有や, 長時間計算が必要な ANNによる関数近似をクラウドで 実行するサーバ（知識共創サーバ）の開発を行う。さらに, 知識共創サーバとへテロジーニアスな MRS を用いて提案手 法の有用性を検証する。

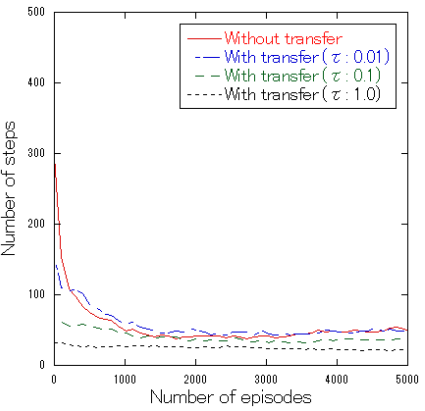

(a) Learning curves of $\mathrm{A}^{-1}$

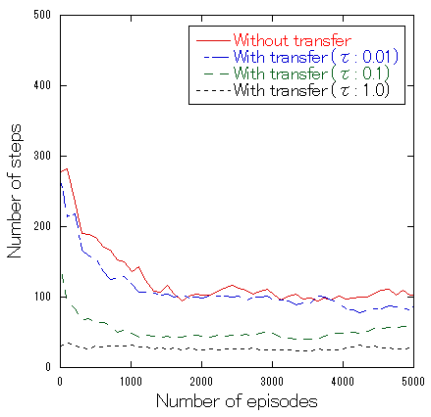

(c) Learning curves of B-1

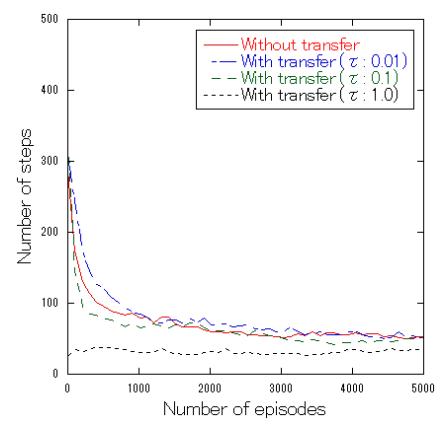

(e) Learning curves of $\mathrm{C}-1$

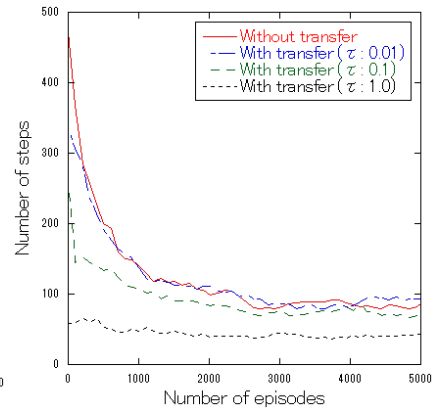

(b)Learning curves of A-2

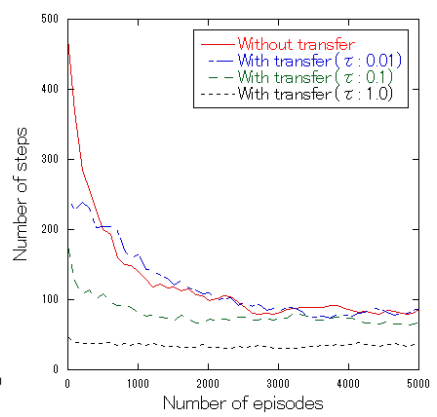

(d) Learning curves of B-2

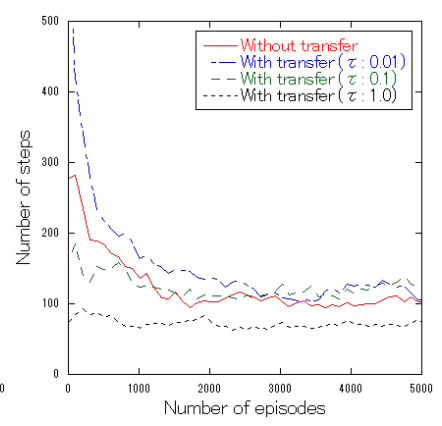

(f) Learning curves of C-2
Table 2 Comparison of initial steps (100 episodes average)

\begin{tabular}{cccc}
\hline $\begin{array}{l}\text { Experimental } \\
\text { condition }\end{array}$ & $\begin{array}{c}\text { Initial steps of source taks } \\
\text { (Average of 100 episodes) }\end{array}$ & $\begin{array}{c}\text { Jump start of target task } \\
\text { (Average of 100 epi. } \tau=1.0 \text { ) }\end{array}$ & $\begin{array}{c}\text { Improvement } \\
\text { rate }\end{array}$ \\
\hline \hline A-1 & 165.72 & 29.55 & 0.82 \\
A-2 & 441.77 & 55.46 & 0.87 \\
B-1 & 349.76 & 30.73 & 0.91 \\
B-2 & 411.77 & 46.39 & 0.89 \\
C-1 & 192.19 & 48.93 & 0.75 \\
C-2 & 349.76 & 97.71 & 0.72 \\
\hline
\end{tabular}

Table 3 Comparison of convergent value (100 episodes average)

\begin{tabular}{cccc}
\hline $\begin{array}{c}\text { Experimental } \\
\text { condition }\end{array}$ & $\begin{array}{c}\text { Convergent steps of source taks } \\
\text { (Average of 100 episodes) }\end{array}$ & $\begin{array}{c}\text { Convergent steps of target task } \\
\text { (Average of 100 epi. } \tau=1.0)\end{array}$ & Error rate \\
\hline \hline A-1 & 59.80 & 27.84 & 0.53 \\
A-2 & 76.96 & 72.60 & 0.06 \\
B-1 & 112.15 & 29.04 & 0.74 \\
B-2 & 76.96 & 35.13 & 0.54 \\
C-1 & 58.99 & 38.81 & 0.34 \\
C-2 & 112.15 & 80.54 & 0.28 \\
\hline
\end{tabular}

\section{文 献}

[1] E. Yang and D. Gu "A Survey on Multiagent Reinforcement Learning Towards Multi-Robot Systems", in Proc. of the IEEE Symposium on computational Intelli- gence and Games, ID2012 , 2005.

[2] M. Mataric, "Reinforcement Learning in the Multi-Robot domain", Autonomous Robots, vol.4, iss.1, pp.73-83, 1997.

[3] S. Arai, K. Sycara and T. R. Payne, "Experience- Based Reinforcement Learning to Acquire Effective Behavior in a Multi-agent Domain”, PRICAI 2000 Topics in Artificial Intelligence, pp.125-135, 2000.

[4] M. Waibel, M. Beetz, J. Civera, R. d'Andrea, J. Elfring, D. Galvez-Lopez, K. Häussermann, R. Janssen, J.M.M. Montiel, Alexander Perzylo, B. Schiessle, M. Tenorth, O. Zweigle and M.J.G. (René) Van de Molengraft, "RoboEarth - A World Wide Web for Robots", Robotics \& Automation Magazine, IEEE, Vol.18, No.2, pp 69-82, 2011

[5] H. Kono, K. Sawai and T. Suzuki, "Convergence Estimation Utilizing Fractal Dimensional Analysis For Reinforcement Learning", in proc. of the SICE Annual Conference 2013, pp. 2752-2757, 2013.

[6] 河野仁，澤井圭，鈴木剛，“知識の抽象化と階層化による自律口 ボットの階層的転移学習”, 第 19 回ロボティクスシンポジア, pp. 479-484, 2014.

[7] M. E. Taylor, "Transfer in Reinforcement Learning Domains", Studies in Computational Intelligence, Springer-Verlag, vol. 216, 2009.

[8] 溝口理一郎, “オントロジ一研究の基礎と応用”, 人工知能学会 誌, Vol.14, No.6, pp.977-988, 1999.

[9] C. J. C. H. Watkins and P. Dayan: "Technical Note Q-Learning", Machine Learning, vol. 8, pp.55-68, 1992.

[10] L. Gasser, N. Rouquetto, R. W. Hill, and J. Lieb, "Representing and Using Organizational Knowledge in Distributed AI Systems", Distributed Artificial Intelligence, vol.2, pp.55-78, 1989.

[11] S. Arai, K. Sycara and T. R. Payne, "Experience- Based Reinforcement Learning to Acquire Effective Behavior in a Multi-agent Domain", PRICAI 2000 Topics in Artificial Intelligence, pp.125-135, 2000.

Fig. 5 Experimental results 